\title{
Research on the Innovation of Teaching Mode of the Studio System of Architectural Decoration Majors in Higher Vocational Education under the Perspective of "Integration of Industry and Education"
}

Lu Zhang

Zibo Vocational Institute, Zibo 255314, Shandong Province, China

Abstract: "Studio system" is a typical teaching mode for architectural design majors at present. This paper adopts the method of theoretical elaboration, combined with the teaching experience of higher vocational architectural decoration majors, and through literature review and summarization, proposed the research on the innovation path for the "studio system" teaching model of the higher vocational architectural decoration major with "work process" at its core and oriented by "project result".

Keywords: Integration of industry and education; Architectural decoration majors; Studio system

Publication date: March, 2021

Publication online: 31 March, 2021

"Corresponding author: Lu Zhang, dmiss@126.com

\section{Introduction}

With the rapid rise of Chinese economy, China's vocational education has developed vigorously, which has cultivated and delivered a large number of high-quality and high-skilled talents for socialist modernization. Currently, under the influence of many factors such as the system, the training model of the supply side of the talent training of the architectural decoration major in higher vocational colleges cannot match the job requirements of the demand side of the industry. Strengthening the supply side of vocational education talent training, and deepening the reform of "three educations" has become an important starting point for the current vocational colleges to improve the quality of school operation and talent training. Therefore, the reform and development of vocational education need to further school-enterprise collaboration, deepen the integration of industry, education and research, and explore new ideas and new models of innovative vocational education. It has become an urgent requirement for the current vocational education reform to promote the effective connection of the vocational education chain, talent training chain, and the industry and job chain.

The studio teaching mode is a new type of teaching mode. $\mathrm{Lu} \mathrm{Man}{ }^{[1]}$ studied the requirements for craftsmanship of art and design students in higher vocational colleges in the current era from the students' innovative thinking, design skills, curriculum core, project teaching, and practice creative design teaching, integrating schools and enterprises, combining theory with practice, and cultivating students' craftsmanship in all directions. From the perspective of the integration of industry and education, this paper elaborates on the innovation paths for the studio teaching model of the architectural decoration majors in higher vocational education.

2 Taking innovative applied talents as the training goal, and "result-oriented" as the training principle

With the rapid development of higher vocational 
education, higher vocational colleges have strengthened the cultivation of innovative talents through the 'Three-teaching' reform. The employment rate of college students has increased significantly, and enterprises have gained highly efficient talents, which has eased social employment pressure and relieved the burden on government. In recent years, higher vocational education has focused more on the industrial chain, focused on technology research, determined the main line of resource integration, gathered talents, innovated and developed, and built a mutually beneficial and win-win model.

Strengthen the in-depth cooperation between schools and enterprises, and jointly explore and innovate the teaching mode of higher vocational architectural decoration major. Through the school-enterprise co-building "studio", the schoolenterprise dual-mentor and dual-education system are implemented. Innovative teaching mode with project practice and work process as the core, students' innovative thinking development as the driving force, industry, enterprise, and school cooperation as the foundation, optimize the talent training system and curriculum system, and implement the result-oriented "studio system" teaching model to enhance students' innovative skills and hard-working craftsman spirit.

Under the "results-oriented" comprehensive sense of innovation, the formation of design results is based on the effective operation of the studio teaching model and the accumulation of student participation in the project. By participating in various design competitions and introducing the real projects of the company into the studio, students participate in real projects under the guidance of dual-mentors, and transform the design works to make the students' design works gain market value. Through the integration of industry, education and research, the tripartite collaboration of school, government and enterprise, the goals of talent development and innovation and a win-win situation for entrepreneurship are achieved.

\section{Research on the paths of establishing the "studio system" teaching mode}

As a practical platform for school-enterprise cooperation, the studio not only undertakes profession-related design projects, but also participates in the establishment and implementation of industry-education integrated courses. Form an interrelated, network-like distributed teaching and service platform, providing teachers and students with an open and developing education and teaching environment (Figure 1).

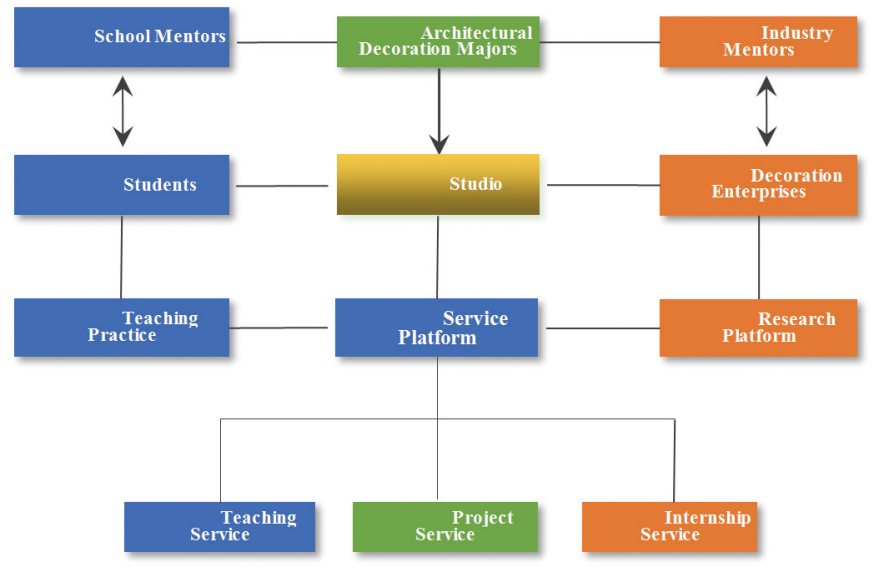

Figure 1. Scheme of studio functions

\subsection{Relying on corporate resources and adva- ntages, build a school-enterprise "integrated" education platform.}

Both the school and the enterprise participate in the personnel training, teaching process and student evaluation system. The enterprise is fully involved in the whole process of talent training, and the two parties have information exchange, personnel assignment, resource sharing, and integration into the corporate culture. Based on in-depth research on school-enterprise cooperative enterprises, 2-3 wellknown local decoration companies were selected to jointly innovate talent training models, and schools and enterprises jointly built "studios" and implement teaching model reforms.

\subsection{Adjust the professional curriculum system according to the needs of the enterprise for the job.}

Enterprises participate in the formulation of professional talent training objectives, training specifications, and training programs, and hire corporate professionals to undertake professional curriculum tasks. According to the analysis on the needs of professional talents for typical positions in the enterprise and the analysis on the status of professional positions, strengthen the students' professionalism, craftsmanship, and labormodel spirit, and enhance the students' innovative spirit, entrepreneurial awareness, teamwork and 
comprehensive professional skills.

3.3 The "studio system" talent training model takes the studio as the main teaching venue, focuses on the typical tasks of decoration enterprises, takes the project as the guidance, and uses the studio as the teaching space to improve the humanistic and professional qualities of students.

When students enter the "studio", they become prospective employees of the company upon signing a quasi-employment agreement, where modern apprenticeship training is implemented and the deep integration of practical teaching and job positions is strengthened to realize practical teaching in the corporate context.

\section{Build a "studio system" operation and management mechanism innovatively}

According to the requirements of higher vocational architectural decoration professional personnel training, the architectural decoration professional studio is divided into interior space design studio and construction drawing deepening design studio, mainly for carrying out works of architectural decoration design, environmental art design, project budget, construction drawing deepening design and drawing, etc.

Through the studio model, students can get in touch with the cutting-edge knowledge of the industry and experience the real work environment in their job practice; give full play to the education value of the studio model, implement the "dual-subjects" education model integrating work and study, and introduce actual industry projects into the classroom teaching. Corporate masters lead students to conduct practical training on real projects, and school teachers provide theoretical guidance, integrate the "dualmentor system" into the teaching process to truly realize a task-driven, project-guided new model of outstanding talent training that combines work and learning.

\subsection{Establish a robust "studio system" operation and management mechanism}

Implement the "result-oriented" studio teaching model to cultivate innovative technical talents. According to the needs of cultivating innovative talents at different levels, students choose to enter the interior space design studio or the construction drawing deepening design studio according to their interests and their own characteristics. The school can classify and train students when organizing teaching and set up different professional development curriculum systems according to the characteristics of the studio.

Innovate teaching management mode and implement credit system reform. Students participate in various types of teaching and practical activities under the joint guidance of dual-mentors from school and enterprise. After completing the public basic modules and architectural decoration major technical basic courses arranged by the school, students choose the corresponding studio courses independently, and realize the management goals of the credit system through the format of "compulsory + optional".

Establish an effective incentive mechanism to promote technological innovation and the training of outstanding talents. Companies set up scholarships and stipends, implement talent training scholarship programs, and set up scholarships and stipends named after enterprises to help vocational education talent training.

\subsection{Implement modern apprenticeship traini-} ng, and effectively promote the "modern apprenticeship" of architectural decoration engineering technology and deep cooperation with cooperative enterprises.

Both the school and the enterprise jointly complete the entire process of talent training. The school and enterprise jointly set up an outstanding talent training leading team, build a platform for the integration of industry and education in the school, and establish a modern apprenticeship coordinating organization.

4.2.1 Formulate "modern apprenticeship teaching management system", "modern apprenticeship credit system management and flexible credit system management measures" and other systems and management methods.

4.2.2 Establish an assessment and evaluation mechanism involving multiple parties. Introduce an enterprise assessment mechanism, and establish a teaching quality monitoring mechanism in the form of regular inspections and feedback. It focuses on assessing students' knowledge application ability, innovation ability, problem 
finding, problem solving ability, and projecthandling ability to promote the comprehensive development of students' professional quality.

\subsubsection{Establish apprenticeship management methods to protect the rights and interests of apprentices. According to teaching needs, scientifically arrange apprentice positions and assign work tasks to ensure reasonable remuneration for apprentices. Implement liability insurance and work injury insurance for apprentices to ensure personal safety.}

\subsection{Building a "diverse" evaluation system and a "dual" education system}

4.3.1 Establish a quality evaluation system for training "multi-disciplinary, Multi-dimensional" talents jointly with schools and enterprises

According to the working standards of the enterprise, the school and the enterprise jointly develop a "multidisciplinary, multi-level" talent training quality evaluation system. "Multi-disciplinary" means that school teachers, business leaders and apprentices can all be the main evaluation targets. "Multidimensional" means representing the objective of the evaluation from different perspectives such as students' school assignments, academic reports, exams, papers, and corporate design project results. According to the evaluation objectives, detailed evaluation rules are written, and the student's homework, transcripts, etc. will follow the evaluation method, with school teachers and corporate mentors as the dual-subjects. Dual-mentors participate in student assessments, and students also conduct self-assessment. Students' performance will be assessed according to the assessment system. Process assessment and comprehensive assessment should be strengthened, and students' comprehensive scores should be recorded in the assessment system and used as reference materials for company talent selection after graduation.

\subsubsection{Build a "mutually beneficial and sharing, heterogeneous complementing" teaching team}

In terms of the composition of the teaching staff, higher vocational colleges can systematically optimize the existing teaching staff, hire wellknown designers, or build a teaching team with teachers to ensure the innovation consciousness of the teaching staff. Introducing advanced design concepts and practical skills in the studio teaching process to meet the needs of industry companies for the job chain. For students with strong creativity, both schools and enterprises must actively increase investment, optimize the teaching team and provide good conditions. Meanwhile, establish and improve the evaluation standards of the teaching team, and stimulate the enthusiasm of the teaching team through incentive measures, which can accumulate more practical experience and improve the core value and market competitiveness of the enterprises ${ }^{[2]}$.

Combining the teaching characteristics and development needs of the studio system, the school and the enterprise jointly improve the dual-track system, establish an adequate dual-track selection, training, assessment and incentive system, and establish a school-enterprise "mutual employment and sharing" teacher management mechanism. According to the selection criteria of "dual-mentors", establish a "corporate tutor bank" and a "skill master bank" for architectural decoration majors, and strengthen the construction of a team of dual-mentors ${ }^{[3]}$.

The "dual-mentors" of schools and enterprises implement dual assessments, equal competition, performance-based appointments and dynamic management. Schools and enterprises jointly establish a regular professional training system, establish a school-enterprise joint leadership team, communicate and cooperate regularly, jointly formulate talent training programs, and jointly steer the direction of profession building and teaching reform. Schools and enterprises jointly establish a "one-to-one" connection system between young backbone teachers and enterprise technology or enterprise backbones, prepare for lectures and teach together, and share vocational education and technical experience. Strengthen the education and promotion of "dualmentors" in order to jointly improve the overall level of the professional training teams ${ }^{[4,5]}$.

\section{Conclusion}

Through the introduction of enterprises into the school, integrate the resources of schools and enterprises, implement the in-depth integration of schools and enterprises, establish shared studios between schools and enterprises, and innovate studio operating mechanisms. Implementation of the "studio 
system" talent training model for higher vocational architectural decoration majors with "work process" as the core and "project results" as the orientation. The curriculum system has been transformed from traditional classroom teaching to project-oriented teaching in project studios under the responsibility of dual-mentors; teachers and students participate in the project process by introducing real projects from the enterprises. Building a studio-based teaching model centered on "teaching projectization and results socialization" in order to innovate talent training models, comprehensively improve the quality of education, enhance students' core competitiveness and job adaptability, and effectively train high-quality technical skills talents required by industry positions.

\section{References}

[1] Lu M. Research on the teaching reform of craftsman spirit of art design majors in higher vocational colleges [J]. Knowledge Library, 2020(19):107+109.

[2] Xie ZM, Yang M. A study of training mode of modern apprenticeship in design specialty of higher vocational colleges in the inheritance of national culture [J]. Art and Design (Theory), 2020, 2(10):147-149.

[3] Tian XH. Teaching reform and practice of art design theory course group under the training target of applied innovative talents — Take the art design major of the Art College of Jilin University as an example [J]. China Journal of Multimedia and Network Teaching (Early Issue), 2020(10):108-110.

[4] Zhu XX. Research on the innovation path of higher vocational art design professional courses under the mixed teaching mode [J]. Food Research and Development, 2020, 41(15):242.

[5] Niu SJ, Zhang MM. Analysis and implementation of the studio teaching mode of environmental art design specialty in higher vocational education [J]. Comparative Study of Cultural Innovation, 2020, 4(22):52-54. 